\title{
EXTRAÇÃO DE TANINO DA CASCA DO CAFÉ
}

\author{
$\mathrm{T}^{1}$.D de ALMEIDA ${ }^{1}$, B.F.MAI ${ }^{1}$, F.P.PUGET \\ ${ }^{1}$ Faculdades Integradas de Aracruz, Departamento de Engenharia Química \\ E-mail:tuliodyaz@hotmail.com
}

\begin{abstract}
RESUMO- O Brasil apresenta-se como um país com alto consumo de café. Entretanto, esse alto consumo gera grande quantidade de resíduos, já que a quantidade de casca que se obtém durante o beneficiamento do café é similar a quantidade de grãos beneficiados. Com a finalidade de minimizar os impactos causados pelo incorreto gerenciamento desse resíduo, esse trabalho teve como objetivo reaproveitar a casca do café Conilon (Caffeacanephora) para extrair taninos condensados. Utilizado em diversas aplicações industriais, como por exemplo, no tratamento de água, o tanino pode ser definido quimicamente como um polifenol de alto peso molecular. Os ensaios utilizando água como agente extrator foram realizados em triplicata, adicionando-se $10 \mathrm{~g}$ de casca a $250 \mathrm{~mL}$ de água destilada, ou de solução alcoólica a $70 \%$ (v/v), que foram utilizados como extratores. Foram avaliados os tempos de 1, 2, 4 e 6 horas, e foi observado que o período mais longo possibilitou alcançar um total de $8,49 \%(\mathrm{~m} / \mathrm{m})$ de taninos condensados quando a água foi usada como agente extrator.
\end{abstract}

\section{INTRODUÇÃO}

Conhecida como café Robusta, o Coffeacanephora apresenta diversas variedades, sendo a Kouilou, a variedade mais utilizada no Brasil, denominada aqui como Conilon (FERRÃO, 2004). Essa variedade de café se encaixa em um genótipo que apresenta tendência ao crescimento arbustivo com ramificações nos caules, florescimento prematuro, folhas alongadas, resistência à seca e maior vulnerabilidade a doenças (FERRÃO, 2004).

Segundo Abic (2012), no Brasil houve um aumento de 3,09\% no consumo de café, no período compreendido entre Nov/11 e Out/12, quando comparado ao período compreendido entre Nov/10 a Out/11, quando haviam sido consumidas 19,7 milhões de sacas. Esse aumento no consumo de café gerou um aumento expressivo na quantidade de cascas, pois estas são o principal resíduo do beneficiamento de café. De acordo com Andrade (2011), a quantidade de cascas pode se igualar à quantidade de grãos beneficiados, dependendo da espécie processada. Atualmente as principais aplicações dessas cascas são a alimentação animal e a aplicação no solo como adubo, entretanto, diversos autores (BRAND, 2000, RIBEIRO FILHO et al., 2000, ANDRADE, 2011, FARAH; DONANGELO, 2006) mostram que essas cascas podem ser usadas como fonte de obtenção de taninos. 
Taninos podem ser definidos quimicamente como sendo compostos que formam soluções coloidais, apresentando reação ácida com forte sabor adstringente quando em contato com água (CARNEIRO, 2006). Nas plantas terrestres os taninos podem ser divididos em dois grupos: taninos hidrolisáveis e taninos condensados, também conhecidos como proantocianidinas. Os taninos hidrolisáveis podem ser divididos em duas sub-classes de acordo com a sua estrutura: galotaninos e elagitaninos. Por outro lado, os taninos condensados são oligômeros ou polímeros de unidades flavonoides unidas por ligações carbono-carbono. Não são suscetíveis à clivagem por hidrólise e não contém restos de carboidratos, como os taninos hidrolisáveis. O grau de polimerização desse grupo de taninos pode ser descrito pelo tamanho das moléculas, podendo atingir massas moleculares superiores a $20 \mathrm{kDa}$, contendo de 2 a 50 ou mais unidades flavonoides (VERZA, 2006).

Nas plantas, os taninos podem estar distribuídos na raiz, folha, fruto, casca e madeira, entretanto em virtude das diferentes espécies não é possível afirmar o valores exato do teor desses compostos em cada parte da planta. A quantidade de taninos presentes nos vegetais pode ser influenciada tanto por fatores ambientais como por fatores intrínsecos a natureza do próprio vegetal. Espécies com elevado teor de taninos, como por exemplo a acácia negra, apresentam uma elevada concentração de taninos nas cascas da base do tronco, mas diminui conforme se aproxima do topo da árvore. Os taninos hidrolisáveis se apresentam em concentrações elevadas nos frutos verdes, mas diminuem à medida que eles amadurecem, e os condensados, que são conhecidos por estarem presentes em quase todas as plantas, estão presentes na casca de todas as folhosas e coníferas e no cerne de várias essências florestais. Acredita-se que os taninos evitam o ataque de microrganismos patogênicos nos vegetais devido a comprovada atividade em combatê-los (CARNEIRO, 2006).

Os taninos podem ser utilizados na indústria alimentícia como antioxidante em sucos de frutas e bebidas, como coagulantes e floculantes no tratamento de água, na produção de borrachas e, como uma de suas principais aplicações, no curtimento de couro (VERZA, 2006). Tendo em vista a importância desse composto, o presente trabalho teve como objetivo extrair taninos condensados da casca do café Conilon, valorizando assim esse principal resíduo do beneficiamento do café.

\section{METODOLOGIA}

\subsection{Preparação do Material}

Para realização dos experimentos, no mês de junho foi coletado $1 \mathrm{~kg}$ de cascas do café Conilon em uma fazenda produtora de café localizada no norte do Espírito Santo. No laboratório de pesquisas das Faculdades Integradas de Aracruz (FAACZ) as cascas foram secas até atingir um teor de umidade constante (em torno de 15\%) para serem utilizadas em seguida na etapa de extração. 


\subsection{Extração e Determinação do Teor de Taninos Condensado}

A extração do tanino foi realizada utilizando água quente e etanol como agentes extratores. Nos experimentos foram seguidos os parâmetros sugeridos por e Paes et al. (2006), entretanto, foram feitas algumas adaptações. Para extração de tanino com água quente foram utilizadas amostras de $10 \mathrm{~g}$ de cascas secas. As amostras foram colocadas em um balão de destilação de $500 \mathrm{~mL}$, onde foi adicionada água destilada, numa relação água/casca de 25:1. Para a extração do tanino com o etanol, foi realizada primeiramente uma lavagem das cascas usando o tolueno, visando remover as graxas e ceras, que normalmente estão presentes na casca, e que também são solubilizadas no álcool. Desta forma, o tolueno remove estes materiais que poderiam contribuir para a fração de materiais não tânicos (TRUGUILHO,2003). Após esta limpeza, deixou-se o material secar em estufa para eliminar o tolueno residual por volatilização. Em seguida foi realizada a extração com etanol, sendo utilizadas $10 \mathrm{~g}$ de amostras de cascas secas. As amostras foram colocadas em balões de destilação de $500 \mathrm{~mL}$ também, numa relação água/casca de 25:1.

Para ambas as extrações, utilizando água quente e a sequência de tolueno e etanol, o balão de destilação foi adaptado a um extrator do tipo Soxhlet. Os tempos de extração usados foram 1, 2, 4 e 6 horas a fim de descobrir qual ofereceria maior eficiência de extração de taninos condensados.

Após a extração, o material foi separado por filtração simples, e do extrato (parte líquida), retirou-se uma alíquota de $100 \mathrm{~mL}$, que foi colocada na estufa a $60{ }^{\circ} \mathrm{C}$ até atingir peso constante, para a determinação do índice de Stiansy. Para a determinação do teor de taninos condensados foi utilizada a metodologia apresentada por Truguilho et al.(2003) com algumas modificações. Do extrato obtido em cada extração retirou-se uma alíquota de 100 $\mathrm{mL}$, a qual foi adicionada $10 \mathrm{~mL}$ de formaldeído e $5 \mathrm{~mL}$ de ácido clorídrico concentrado, deixando-se descansar por um período de 24 horas. Sob essas condições os taninos condensados formam complexos insolúveis, que podem ser separados por filtração simples. $\mathrm{O}$ precipitado removido foi colocado em uma placa de petri previamente tarada, para secagem em estufa a uma temperatura de $60{ }^{\circ} \mathrm{C}$ até atingir peso constante. Todos os ensaios foram realizados em triplicata.

O teor de extrativos totais (TET (\%)) extraídos usando água quente e a sequência tolueno e etanol foi calculado empregando a Equação 1:

Onde $m_{i}$ é a massa de casca antes da extração e $m_{\mathrm{f}}$ é a massa de casca após a extração. 
Para a determinação do Índice de Stiansy (IS (\%)) foi utilizada a Equação 2:

$I S(\%)=\left(M_{f} / M_{i}\right) * 100$

Onde $\mathrm{M}_{\mathrm{i}}$ é a massa de sólido presente em $100 \mathrm{~mL}$ de extrato após deixa-lo secar em estufa e $\mathrm{M}_{\mathrm{f}}$ é a massa do complexo tanino-formaldeído precipitado em $100 \mathrm{~mL}$ de extrato.

Para determinar o teor de taninos condensados no extrato (TTCE (\%))foi empregada a Equação3:

$\operatorname{TTCE}(\%)=(T E T * I S) / 100$

Para determinar o teor de taninos condensados na casca do café (TTC (\%)) foi utilizada a Equação 4:

$T T C(\%)=(T E T * T T C E) / 100$

\section{RESULTADOS E DISCUSSÕES}

Seguindo a metodologia proposta, os dados obtidos a partir da extração com água quente foram apresentados na Tabela 1.

Verificando os dados, pode-se constatar que o teor de extrativos totais (TET) permaneceu praticamente constante durante o período de 1 a 6 horas, o que leva a inferir que o (TET) extraído não depende do tempo de extração. Verifica-se ainda, que neste mesmo período de tempo o teor de taninos condensados na casca do café (TTC) dobrou. Autores como Truguilho et al., (2003); Paes et al., (2006) e Pansera, (2003) deixam claro que o teor de taninos presentes em uma determinada planta depende da espécie em si e não da quantidade de extrativos totais pois, junto com estes podem ter muitos outros compostos que não sejam taninos. 
Tabela 1-Teores de extrativos totais (TET), Índice de Stiansy (IS), teor de taninos condensados no extrato(TTCE) e teor de taninos condensados na casca (TTC) obtidos a partir da extração com água quente.

\begin{tabular}{ccccc}
\hline Tempo $(\mathrm{h})$ & TET $(\%)$ & IS (\%) & TTCE (\%) & TTC (\%) \\
\hline 1 & $35,93 \pm 0,17$ & $32,26 \pm 1,17$ & $11,59 \pm 0,47$ & $4,16 \pm 0,18$ \\
2 & $37,05 \pm 0,14$ & $32,35 \pm 2,6$ & $11,99 \pm 1,01$ & $4,44 \pm 0,39$ \\
4 & $37,79 \pm 0,31$ & $58,82 \pm 2,14$ & $22,23 \pm 0,99$ & $8,40 \pm 0,44$ \\
6 & $37,99 \pm 0,15$ & $58,82 \pm 1,16$ & $22,35 \pm 0,53$ & $8,49 \pm 0,23$ \\
\hline
\end{tabular}

Para uma melhor visualização dos resultados, com base na Tabela 1, montou-se a Figura 1, que mostra o teor de taninos condensados na casca do café Conilon, para os diferentes tempos testados:

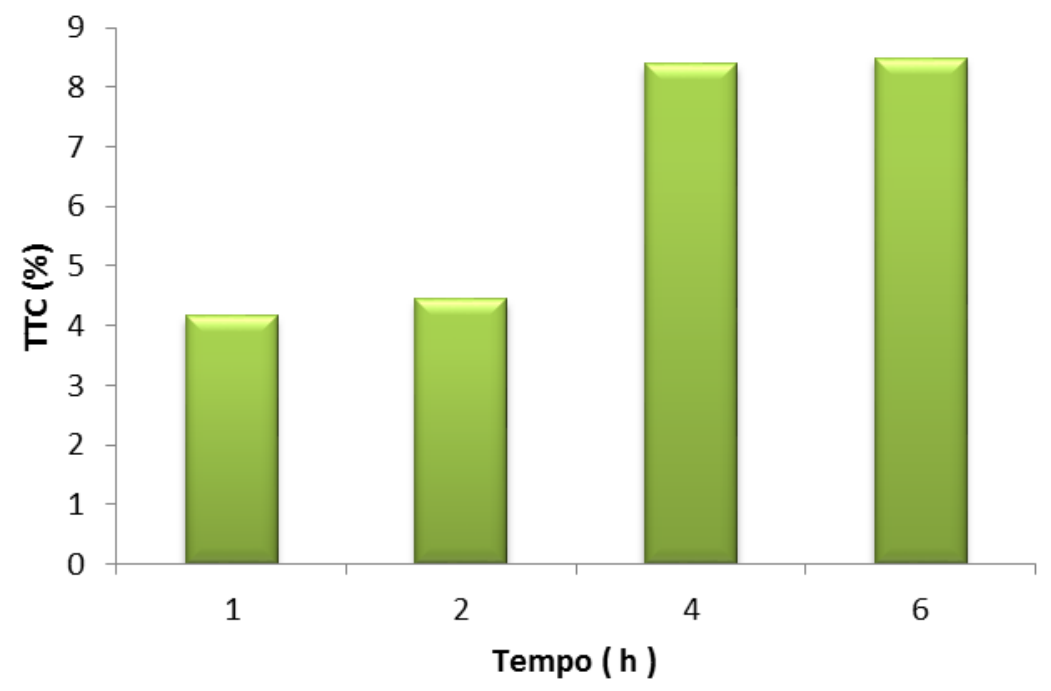

Figura 1- Teor de taninos condensados na casca (TTC) em base de casca seca.

A partir da Figura 1 pode-se inferir que os tempos de quatro e seis horas foram os que possibilitaram maior extração de taninos condensados da casca do café Conilon $(8,49 \%)$. O teor de taninos na casca do café encontrado no presente trabalho está de acordo com os valores encontrados na literatura, como exemplo o valor encontrado por Andrade (2011) (6,3\%), e os valores encontrados por Ribeiro Filho (1998), citado por Vilela (1999), que realizou um levantamento da composição química da casca do café para diferentes nutrientes, dentre eles o tanino, encontrado um valor mínimo e um máximo de 1,31 e 2,97\% respectivamente, não se aproximando mais do valor encontrado por estes autores em virtude das diferentes espécies utilizadas em cada trabalho, o que ocasiona diferença nos percentuais alcançados. Verificou-se ainda que não é vantajoso, por exemplo, extrair tanino no tempo de seis horas pois pode se obter praticamente o mesmo teor no tempo de quatro horas. 
Tabela 2- Teor de extrativos totais (TET) obtidos a partir da extração com álcool

\begin{tabular}{cc}
\hline Tempo $(\mathrm{h})$ & TET $(\%)$ \\
\hline 1 & 38,36 \\
2 & 39,54 \\
4 & 40,23 \\
6 & 42,81 \\
\hline
\end{tabular}

Da Tabela 2, verifica-se que a extração com álcool, obteve um maior teor de extrativos totais, quando comparada com a extração com água quente. As diferenças na quantidade de taninos solubilizados nos dois métodos pode ser explicada pelo fato de que uma fração dos extratos solúveis em água quente também são solúveis em solventes orgânicos (TRUGILHO, 2003). Entretanto, não foi possível utilizar os extrativos para determinar o teor de taninos condensados seguindo a metodologia proposta. Não houve a formação de precipitado, complexo tanino-formaldeído, quando se adicionou o formaldeído e o ácido clorídrico, impossibilitando calcular o índice de Stiansy e consequentemente o teor de taninos condensados presentes na casca do café.

\section{CONCLUSÃO}

A extração de taninos condensados foi realizada com êxito utilizando água como extrator e o método de Stiansy para quantificação, comprovando assim a eficácia do método, já que os valores encontrados estão de acordo com os valores da literatura. $\mathrm{O}$ percentual de taninos extraído não foi muito alto se comparado com outras espécies produtoras de tanino. Entretanto, em virtude da fácil aquisição e da grande disponibilidade do resíduo pode-se considerar a casca do café Conilon como uma matéria-prima promissora para a obtenção de taninos condensados.

\section{REFERÊNCIAS}

ANDRADE, K.S., Avaliação das técnicas de extração e do potencial antioxidante dos extratos obtidos a partir de casca e de borra de café (Coffea arábica L.). Programa de Pós Graduação em Engenharia de Alimentos. Universidade Federal de Santa Catarina, Centro Tecnológico, Florianópolis, 2011.

\section{CARNEIRO, A.C.O., Efeito da hidrólise ácida e sulfitação de taninos de Eucalyptus} grandis W. Hillex Maiden e Anadenanthera peregrina Speg, nas propriedades dos adesivos. Tese. Programa de Pós-Graduação em Engenharia Florestal. Universidade Federal de Viçosa, Minas Gerais, 2006.

FERRÃO, R.G., Biometria aplicada ao melhoramento genético do café Conilon. Tese . Programa de Pós-Graduação em Genética e Melhoramento. Universidade Federal de Viçosa, Minas Gerais, 2004. 
FONSECA, A.F.A.; FERRÃO, M.A.G.; FERRÃO, G.R., A cultura do café Robusta. I

Simpósio de Pesquisa dos Cafés do Brasil. Disponível em: http://www.sbicafe.ufv.br/ handle/10820/22 acessado em 20/Abril/2014 às 14:00 h.

PAES, J.B.; DINIZ, C.E.F.; MARINHO, I.V.; LIMA, C.R., Avaliação do potencial tanífero de seis espécies florestais de ocorrência no semi-árido brasileiro. Artigo. Cerne, Lavras, v. 12, n. 3, p. 232-238, jul./set. 2006.

TRUGILHO, P.F.; CAIXETA, R.P.; LIMA, J.T.; MENDES, L.M., Avaliação do conteúdo. TRUGUILHO, P.F.; MORI, F.A.; LIMA, J.T.; CARDOSO, D.P., Determinação do teor de taninos na casca de Eucalyptus spp. Cerne, Lavras, v. 9, n. 2., p. 246-254, jul./dez. 2003.

VERZA, S.G., Avaliação das variáveis analíticas dos métodos de determinação do teor de taninos totais baseados na formação de complexos com substâncias proteicas e derivados da polivinilpirrolidona. Dissertação. Programa de Pós-Graduação em Ciências Farmacêuticas. Universidade Federal do Rio Grande do Sul, Porto Alegre, 2006.

VILELA, F.G., Uso da casca de café melosa em diferentes níveis na alimentação de novilhos confinados. Dissertação. Programa de Pós-Graduação em zootecnia. Universidade Federal de Lavras, Minas Gerais, 1999. 